\title{
Nutritional Analysis of Edible Wild Fruit (Zizyphus Jujuba Mill.) Used By Rural Populace of District Hamirpur, (H.P.), India
}

\author{
Anju Batta Sehgal ${ }^{*}$ and S.K. Sood ${ }^{2}$ \\ *Associate Professor Deptt. Of Botany Govt. P.G. College Hamirpur (H.P.) \\ ${ }^{2}$ Professor Deptt. Of Biosciences Himachal Pradesh University, Shimla.
}

\begin{abstract}
Wild edible plants form an important constituent of traditional diets in Himalayas. People of Hamirpur District are very close to Nature wild fruits like Zizyphus jujuba Mill. are one of the important natural resources in the district. The indigenous people of the district have direct dependence on the wild plants for their sustenance. Hundreds of wild edible plants are present in the north-western Himalayas, out of which the 'Ber' Zizyphus jujuba Mill. has its religious as well as nutritional advantage over the others. Because of the easy accessibility the fruits are very commonly eaten by the rural populace and the travellers. Biochemical analysis of the dried fruits showed remarkable presence of Carbohydrates $69.12 \%$, Total sugars $27.75 \%$, Phosphorus 133mg/100g, Calcium 199.19mg/100g, Magnesium 84.69mg/100g and Iron 4.15mg/100g on dry weight basis. In other words an important supplementary diet for giving strength to otherwise poor and deprived lot. The present communication aims to highlight the fruits eaten by the inner country side people and what nutritional components are they getting in return.
\end{abstract}

Key Words: Nutritional Analysis, Wild Edible, Hamirpur District, Indigenous.

\section{Introduction}

Himalayas have a great wealth of wild edible plants and traditional inherent knowledge to use it. The land is a rich repository of edible plants. About 1000 species are consumed as food plants in India chiefly by its 53 million natives or tribal communities under 227 ethnic groups occupying about 18.74 percent of the total area under varied geographical and climatic zones of over 5,000 forested villages (Singh \& Arora, 1978), constituting about $7.7 \%$ of India's population (Sinha, 1996). 675 edibles are known to occur in Indian Himalayas (Samant \& Dhar, 1997), based on the plant parts eaten diversity comprises of roots/tubers 145spp., leafy vegetables $521 \mathrm{sp}$., buds/flowers $101 \mathrm{sp}$., fruits $647 \mathrm{sp}$. and seeds/nuts16sp. (Anon., 1994). The plant of Zizyphus jujuba grows wild on the hill slopes of all five subdivision of Hamirpur. Plant not only provide the edible fruits but also have other importance like fuel, fodder and medicinal value for the rural folks. The evidence of man's dependency on plants for his survival can be demonstrated by palaeo-ethnobotanical findings from prehistoric archaeological sites (Renfrew, 1963), (Smith, 1986). Although rural people utilized wild plants but since late 1980's studies on use of wild plants in tropical forests have been taken up vigorously (Plotkin \& Famolare, 1992a), (Plotkin \& Famolare, 1992b). The naturally growing wild fruits were collected from Tikkar Khatrian and Bhareri area of the district. Dried and powdered fruits were analysed for the nutritional components.

\section{Material and Methods}

\section{Study Area}

The study comprises of local villages in Hamirpur, H.P. Himachal Pradesh situated in the lap of northwestern Himalayas, a state with diverse culture and tradition is located between $30^{\circ} 22^{\prime} 40^{\prime \prime}$ north latitudes and $75^{\circ} 45^{\prime} 55^{\prime \prime}$ to $79^{\circ} 04^{\prime} 20^{\prime \prime}$ east longitude. The total area of the state is $55673 \mathrm{Sq} . \mathrm{km}$ with mountains ranging from 350 to $6,975 \mathrm{~m}$ and average rainfall $152 \mathrm{~cm}$. Large variation is observed regarding ethnic uses of plants among people of Himachal Pradesh (Bhalla et al., 2006). Ethnobotanical studies in different parts of Himachal Pradesh have been conducted including the underground plant parts (Sood \& Prakash, 2007). Hamirpur district is situated between $76^{\circ}-17^{\prime}-50^{\prime \prime}$ to $76^{\circ}-43^{\prime}-42^{\prime \prime}$ east longitudes and $31^{\circ}-24^{\prime}-48^{\prime \prime}$ to $31^{\circ}-53^{\prime}-35^{\prime \prime}$ north latitudes, in the south western part of state covered by lower Himalayas.

\section{Methodology}

Field survey, collection of plant and data related to it, was carried out during the period of March 2008 to 2012, the specimens were identified by carefully matching them in the herbarium of Botanical Survey of India northern circle at Dehradun. Ethnic informers were consulted to locate and collect these plants along with the author. Details of this plant were taken by interviewing the local people and elderly persons. Useful informations were gathered. Ripe fruits were dried naturally and fruit powder was analysed. 

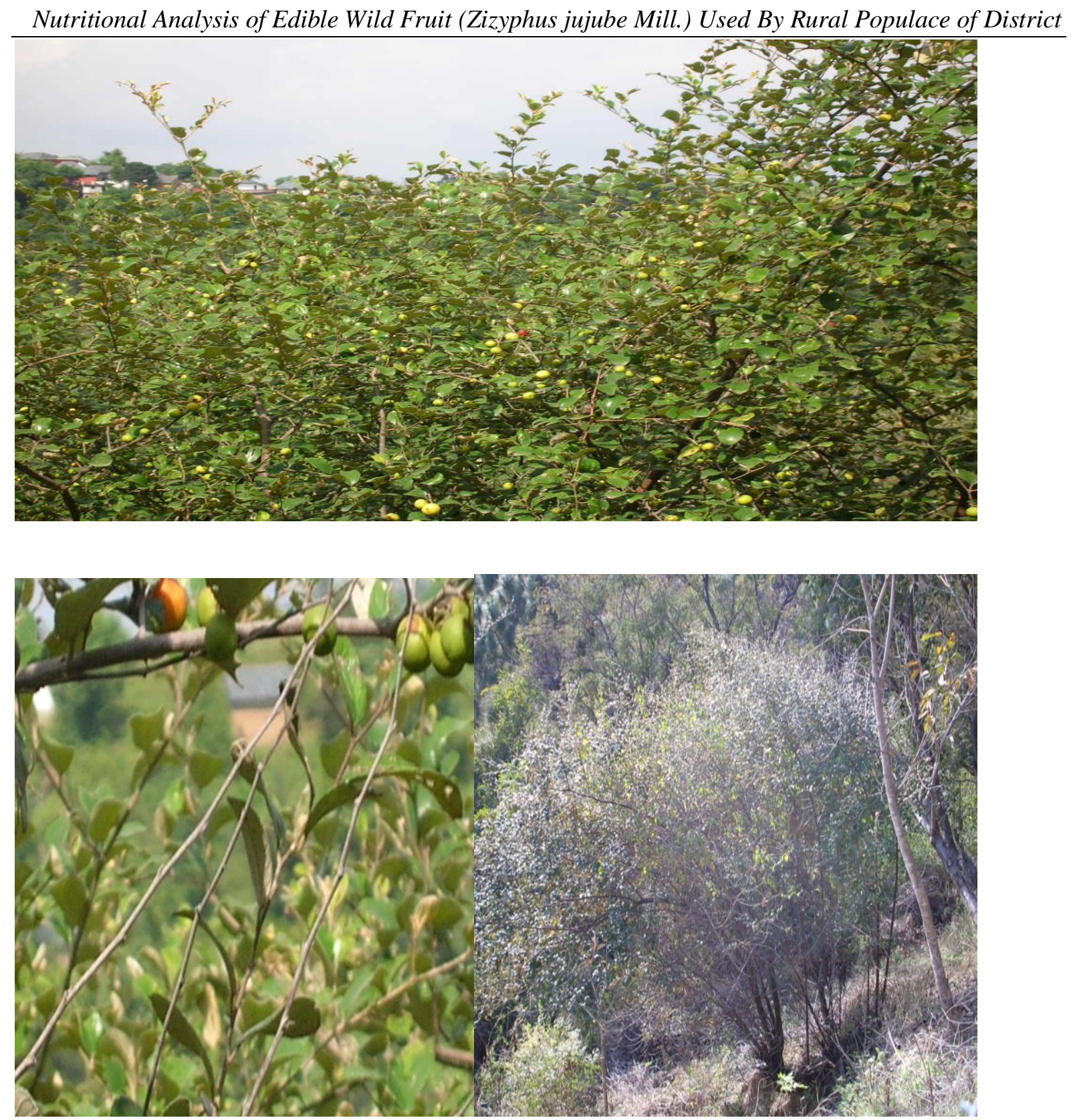

\section{Zizyphus jujuba Mill. Showing Fruits, Habitat and Habit.}

\section{Results}

Biochemical analysis carried out on the wild dry powdered fruit of Zizyphus jujuba showed remarkable results proving that it is not only a pleasure plucking and eating but also a storehouse of lots of required nutrients. Present analysis shows the nutritional components of this fruit, Carbohydrates- 69.12\%, Total Sugars-27.75\%, Fibres-4.77\%, Proteins-4.37\%, Ash content-3.30\%, Potassium-1.49\% and the minerals Phosphorus 133.76 mg/100g, Calcium 199.19mg/100g, Magnesium 84.69 mg/100g, Sodium 16.18 mg/100g and Iron $4.15 \mathrm{mg} / \mathbf{1 0 0 g}$ (Table-1). These fruits are not only acting as supplementary foods but are the tonic requirements of the deprived poor country side people of this district. Carbohydrates and sugars provide energy and Phosphorus, Calcium, Magnesium, Sodium and Iron make their bones to grow stronger. The fruit has great economic value and linked with health condition of the indigenous people of Hamirpur. 


\section{Table-1}

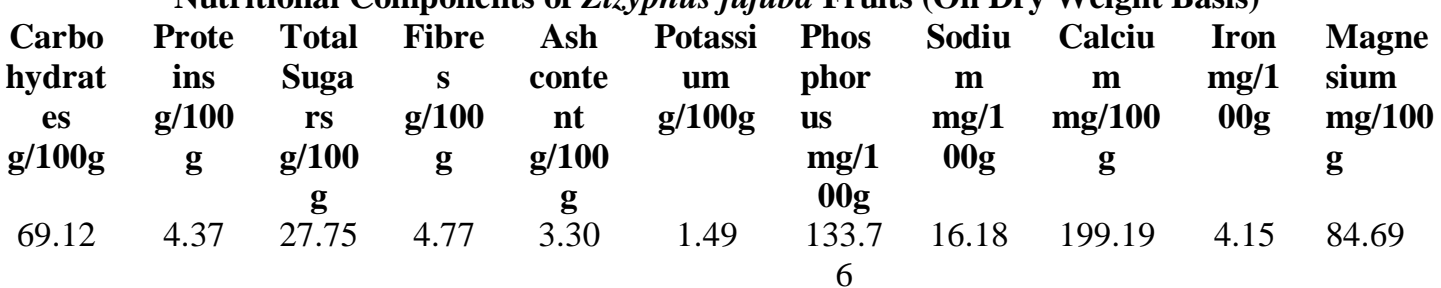

Figure-1 \& 2 depict the quantitative reflection of the nutrients and minerals of the Wild Fruits of Zizyphus jujuba. A few such species may be introduced in agroforestry systems, which could be potential genetic resource for edible fruits breeding programmes in the other areas of the country and also to provide edible plant resources to the communities in addition to creating photosynthetic pool to counter environmental degradation.

\section{Conclusions}

There is an obvious need to explore wild fruits like Zizyphus jujuba which can be easily assessed and harvested without much pressure on the species. This will add a new dimensions towards traditional management and conservation of plant wealth of this region. Utilization of wild edible plant will be an effective tool for restoration of traditional knowledge, inherent in indigenous people. The outcome of such studies and analysis there of will be useful in filling the gaps in nutritional deficiency of poor inhabitants and need for growing supplementary foods as diet.

\section{Acknowledgement}

Author is thankful to the local people for sharing their knowledge regarding the above fruit and its uses in day to day healthcare practices.

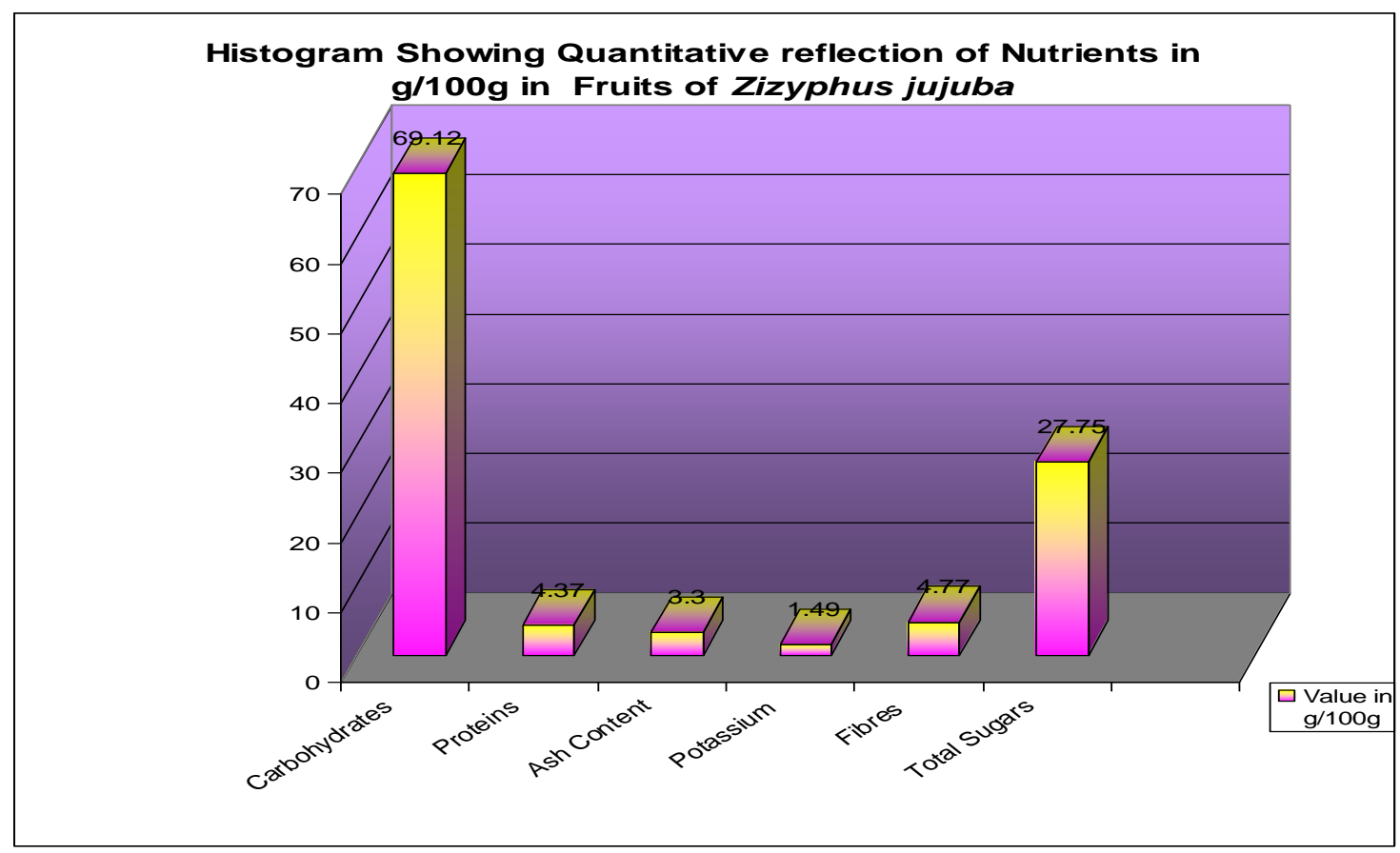

Figure-1 Histogram Showing Quantitative Reflection of Nutrients in Edible Fruits of Zizyphus jujuba in g/100g. 


\section{Histogram showing Quantitative Reflection of Minerals (mg/100g) in Fruits of Zizyphus jujuba}

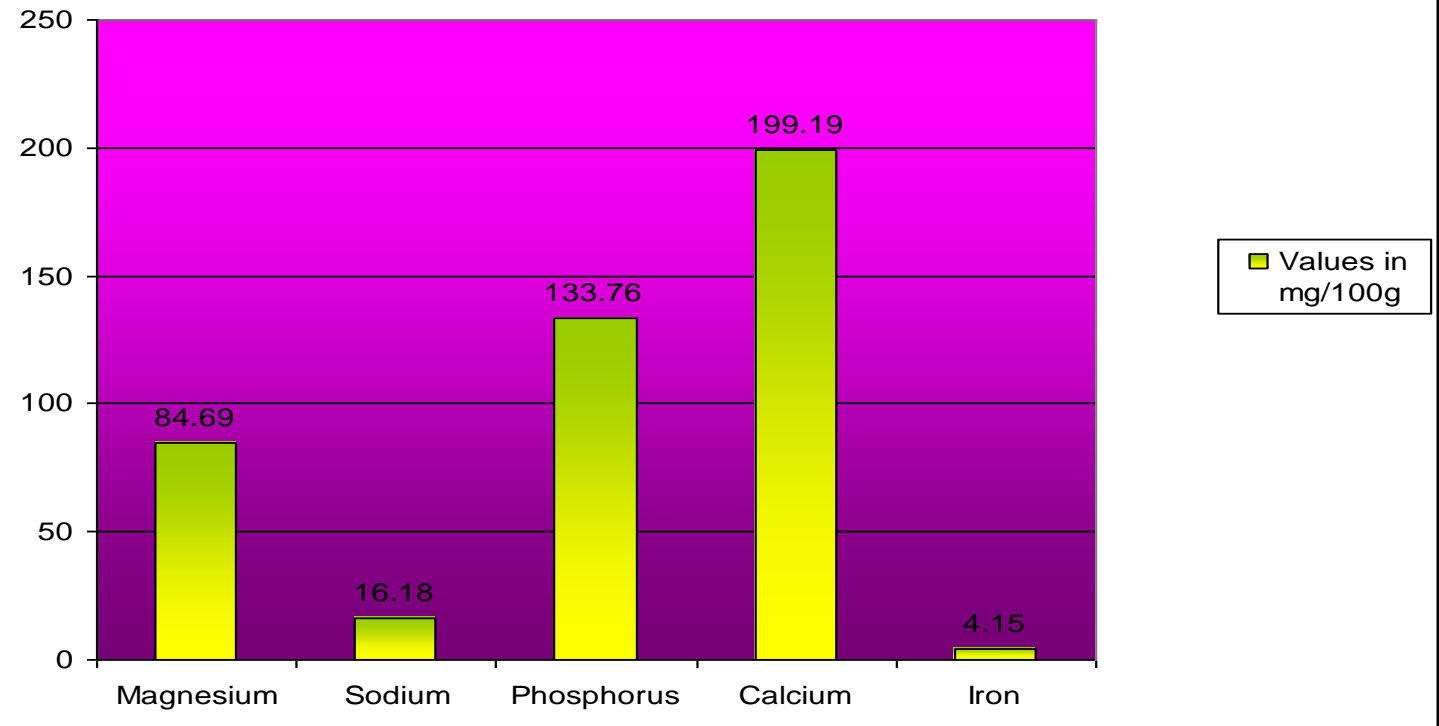

Figure-2 Histogram Showing Quantitative Reflection Of Minerals (mg/100g) in Fruits of Zizyphus jujuba.

\section{References}

[1]. Anonymous, 1994. Ethnobiology in india- a status report. Ministry of environment and forest, govt. Of india.

[2]. Bhalla, s.and bhalla, t.c.2006. Traditional food and beverages of himachal pradesh, indian j. Traditional knowledge 6(1): 17-24.

[3]. Poltkin, m. And famolare, 1.1992a. Non-wood products from tropical rain forests, conservation international, washington, dc.

[4]. Poltkin, m. And famolare, 1.1992b. Sustainable harvest and marketing of rain forests, conservation international, washington, dc.

[5]. Renfrew, j.m. 1963. Paleobotany: the prehistoric food plants of the near east and europe, columbia university press.

[6]. Singh, h.b.\& arora, r.k. 1978. Wild edible plants of india. New delhi, icar.

[7]. sinha, r. K. 1996. Ethnobotany - the renaissance of traditional herbal medicines. Ina shree, jaipur.

[8]. Sood, s.k. \& prakash, v. 2007. Edible roots and underground stems of ethnic india. Satish serial publ., delhi.

[9]. Smith, d. Bruce. 1986. The independent domestication of indigenous seed-bearing plants in eastern north america, center for archeological research, southern illinois university, occasional papers 7. 